\title{
SISTEM INFORMASI GEOGRAFIS PEMETAAN USAHA PINGGIR JALAN POROS MAKASSAR -PARE
}

\author{
Neneng Awaliah ${ }^{1}$, Suryadi Syamsu ${ }^{2}$ \\ Sistem InformasiSTMIK AKBA ${ }^{1}$, Teknik Informatika STMIK AKBA ${ }^{2}$ \\ Email : neneng@akba.ac.id ${ }^{1}$, adi@akba.ac.id ${ }^{2}$
}

\begin{abstract}
ABSTRAK
Jalan poros Makassar - Pare adalah jalan raya yang menghubungkan kota Makassar dan Kota Pare-pare. Jalan poros Makassar - Pare jalan raya yang melewati Kabupaten Maros, Kabupaten Pangkep dan Kabupaten Barru. Jalan raya tersebut sekitar $130 \mathrm{KM}$ dimana dipinggir jalan terdapat banyak jenis usaha pinggir jalan. Sistem informasi geografis salah pilihan untuk memberikan informasi yang tepat dan akurat dalam memberikan informasi lokasi dan jenis usaha pinggir jalan raya. Penelitian ini bertujuan merancang suatu sistem informasi geografis lokasi dan jenis usaha yang ada di jalan poros Makassar - Pare. Data penelitian yang digunakan data primer dan data sekunder. Data primer diperoleh melalui survey dan wawancara, sedangkan data sekunder diperoleh dari dokumen-dokumen. Metode perancangan dari sistem ini menggunakan UML (Unifield Modelling Languge) yaitu menggunakan use case diagram, class diagram, sequence diagram, dan activity diagram. Metode pengujian yang digunakan adalah pengujian black box. Dari penelitian ini dapat memberi informasi kepada masyarkat atau pengguna jalan tentang lokasi dan jenis usaha yang ada di jalan poros Makassar - Pare. Dan dengan adanya informasi dapat meningkatkan penjulan pada usaha-usaha pinggir jalan raya.
\end{abstract}

Kata Kunci: Jalan Raya; Makassar; Sistem Informasi Geografis; Usaha

\begin{abstract}
The Makassar - Pare axis road is a highway that connects the city of Makassar and the City of Pare-pare. The Makassar - Pare main road, which passes through Maros Regency, Pangkep Regency and Barru Regency. The highway is about $130 \mathrm{KM}$ where along the road there are many types of roadside businesses. Geographical information system is the wrong choice to provide precise and accurate information in providing information on the location and type of roadside business. This study aims to design a geographic information system for the location and type of business on the Makassar - Pare axis road. The research data used primary data and secondary data. Primary data were obtained through surveys and interviews, while secondary data were obtained from documents. The design method of this system uses UML (Unifield Modeling Language), which uses use case diagrams, class diagrams, sequence diagrams, and activity diagrams. The test method used is black box testing. From this research, it is hoped that the geographic information system can provide information to drivers on the location and type of business on the Makassar - Pare axis road. And with the information it can increase sales of roadside businesses.
\end{abstract}

Keywords: Highway; Makassar; Geographical Information System; Company 


\section{PENDAHULUAN}

Jalan poros Makassar - Pare adalah jalan raya yang menghubungkan kota Makassar dengan Kota Pare-pare. Jalan poros Makassar - Pare jalan raya yang melewati Kabupaten Maros, Kabupaten Pangkep dan Kabupaten Barru. Jalan raya tersebut sekitar $130 \mathrm{KM}$ dimana dipinggir jalan terdapat banyak jenis usaha pinggir jalan.Usaha-usaha yang saat ini ada di jalan poros Makassar - Pare diantara roti maros, buah jeruk, hasil kerajinan tangan, ikan, jagung, kue serabi dan lain sebagainya. Namun terkadang masih ada pengendara yang tidak mengetahui lokasi usaha-usaha tersebut.

Sistem Informasi Georafis atau Georaphic Information Sistem (GIS) merupakan suatu sistem informasi yang berbasis komputer, dirancang untuk bekerja dengan data yang tereferensi secara spasial atau koordinat-koordinat geografi. Dengan memanfaatkan teknologi Sistem Informasi Georafis atau Georaphic Information Sistem (GIS)masyarakat atau pengendara akan lebih mudah dalam mengetahui lokasi usaha dan jenis usaha usaha yang ada di jalan poros Makassar - Pare.

Berdasarkan pemaparan maka peneliti merancangsistem informasi geografis pemetaan usaha pinggir jalan raya, dengan studi kasus jalan poros Makassar Pare.Dari penelitian ini dapat memberi informasi kepada pengendara lokasi dan jenis usaha yang ada di jalan poros Makassar - Pare. Dan dengan adanya informasi dapat meningkatkan penjulan pada usaha-usaha pinggir jalan raya.

\section{LANDASAN TEORI}

2.1 Sistem Informasi Geografis

Sistem Informasi Geografis (SIG) / Geographic Information System (GIS) adalah suatu sistem informasi berbasis komputer, yang digunakan untuk memproses data spasial yang bergeoreferensi (berupa detail, fakta, kondisi) yang disimpan dalam suatu basis data dan berhubungan dengan persoalan serta keadaan dunia nyata (real world). (Masykur et al., 2014)

Teknologi Sistem Informasi Geografis (SIG) adalah sistem komputer yang terdiri dari proses mengumpulkan, memeriksa, mengintegrasikan, dan menganalisa informasi-informasi yang berhubungan dengan area permukaan bumi. Pada dasarnya, istilah sistem informasi geografi merupakan gabungan dari tiga unsur pokok yaitu sistem, informasi, dan geografi. (Anugraha et al., 2020)

Komponen-komponen SIG yaitu perangkat keras, perangkat lunak, data dan informasi geografis, sumber daya manusia, dan prosedur. Informasi lokasi ditentukan berdasarkan sistem koordinat, yang diantaranya mencakup datum dan proyeksi peta. Datum adalah kumpulan parameter dan titik control yang hubungan geometriknya diketahui, baik melalui pengukuran atau penghitungan. Sedangkan sistem proyeksi peta adalah sistem yang dirancang untuk merepresentasikan permukaan dari suatu bidang lengkung atau spheroid (misalnya bumi) pada suatu bidang datar. Proses representasi ini menyebabkan distorsi yang perlu diperhitungkan untuk memperoleh ketelitian beberapa macam properti, seperti jarak, sudut, atau luasan.

\subsection{Pemetaan}

Pemetaan adalah suatu teknik yang secara mendasar dihubungkan dengan kegiatan memperkecil keruangan suatu daerah yang sebagian atau seluruh 
permukaan bumi, atau benda-benda angkasa dan menyajikan dalam suatu bentuk yang dapat mudah diobservasi, sehingga dapat dimanfaatkan untuk kepentingan komunikasi.

Dasar utama dalam pembuatan peta adalah pengadaan sistem koordinat yang dapat menghubungkan antara satu titik dengan titik lainnya. Sistem koordinat geografis adalah suatu sistem koordinat titik di permukaan bumi yang posisinya ditentukan oleh dua perpotongan dua buah garis lengkung bumi (Rais, 2012)

\subsection{Pengertian Usaha}

Usaha menurut Kamus Besar Bahasa Indonesia adalah kegiatan dengan mengerahkan tenaga, fikiran, atau badan untuk mencapai suatu maksud. Pekerjaan, perbuatan, prakarsa, ikhtiar, daya upaya untuk mencapai suatu maksud. Dalam Undang-undang No. 3 Tahun 1982 tentang wajib daftar perusahaan, usaha adalah setiap tindakan, perbuatan, atau kegiatan apapun dalam bidang perekonomian yang dilakukan oleh setiap pengusaha atau individu untuk tujuan memperoleh keuntungan atau laba.(Ismail Solihin, 2006)

\subsection{United Modelling Language (UML)}

UML adalah bahasa spesifikasi standar yang dipergunakan untuk mendokumentasikan, menspesifikasikan dan membangun perangkat lunak.UML merupakan metodologi dalam mengembangkan sistem berorientasi objek dan juga merupakan alat untuk mendukung pengembangan sistem. UML saat ini sangat banyak dipergunakan dalam dunia industri yang merupakan standar bahasa pemodelan umum dalam industry perangkat lunak dan pengembangan sistem.(Cahyono, et al., 2016)

\section{METODE PENELITIAN}

3.1 Jenis dan Sumber Data Jenis dan sumber data dalam penelitian ini sebagai berikut :

a). Data Primer.

Data primer merupakan data yang diperoleh melalui hasil penelitian langsung. Data mentah tersebut diperoleh melalui hasil survei dan wawancara.

b). Data Sekunder.

Data sekunder adalah data yang diperoleh dari berbagai dokumen, dokumen, atau informasi pihak-pihak yang terkait dengan permasalahan dalam penelitian ini. Data sekunder berasal dari brosur atau dokumen perusahaan yang terkait dengan penelitian.

\subsection{Perancangan model sistem}

Perancangan model sistem dalam penelitian ini menggunakan UML (Unified Modeling Language).

\section{a). Use Case Diagram}

Use case diagram dirancang untuk menunjukkan secara umum fungsi dan tanggung jawab masing-masing aktor dalam Sistem Informasi Geografis yang dibangun. Use case diagram dari Sistem Informasi Geografis dapat dilihat pada gambar 1 


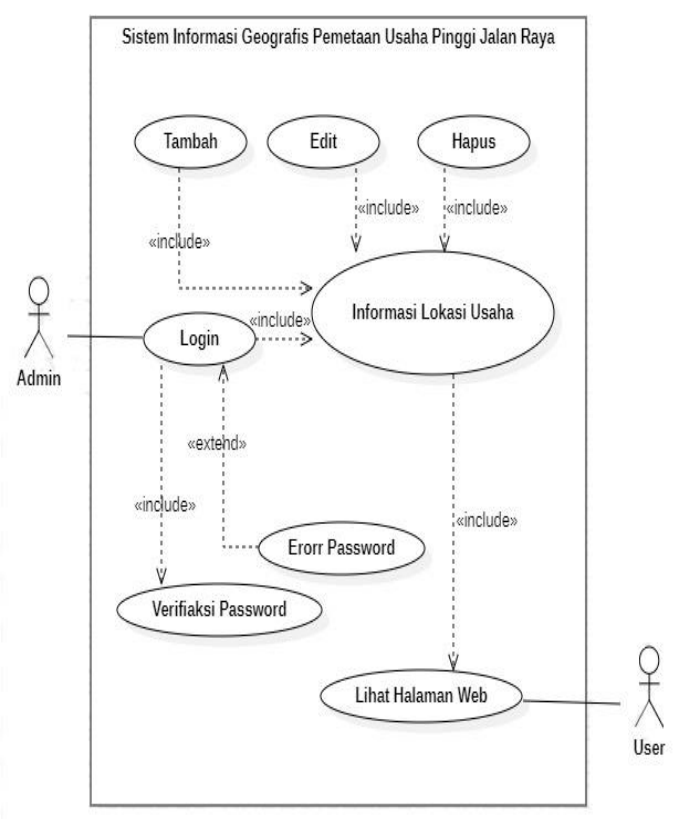

Gambar 1. Use Case Diaram

b). Diagram Activity

Merupakan gambaran tentang aktivitas-aktivitas berurutan yang akan dilakukan pengguna pada sistem informasi geografis pemetaan usaha. Activity diagram dapat dilihat pada gambar 2 dan Gambar 3..

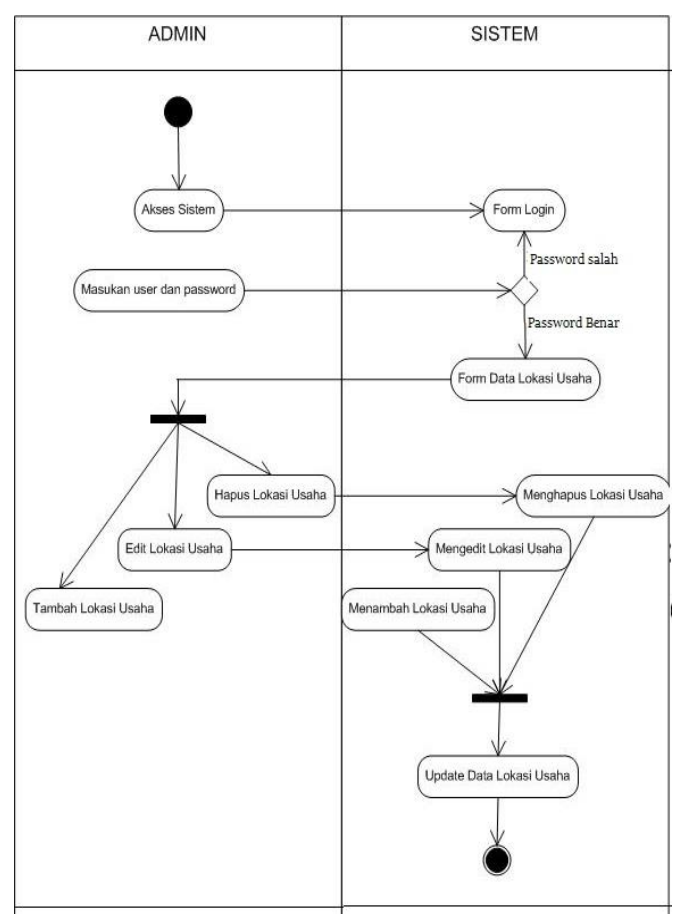

Gambar 2. Activity Diagram Admin
Gambar 2 Activity diagram admin menjelaskan proses alur bagaimana admin dapat melihat mengakses dan mengolah datapada sistem informasi geografis.

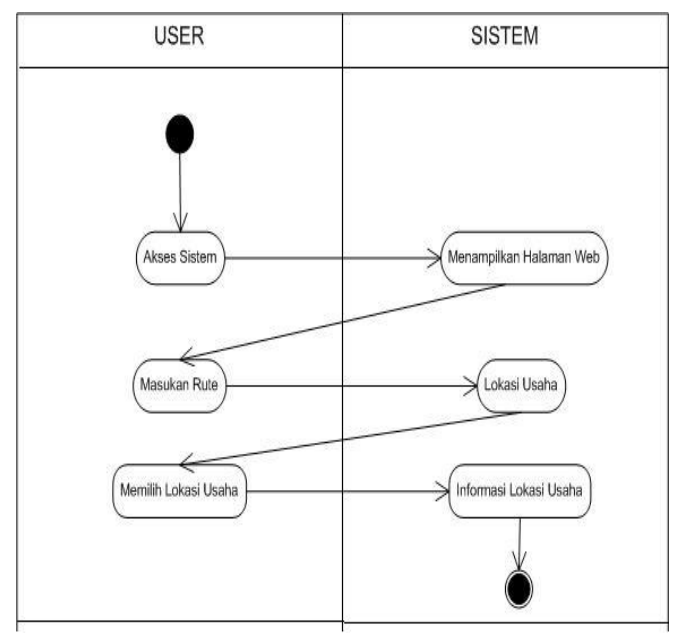

Gambar 3. Activity Diagram User

Gambar3 Activity diagram user menjelaskan proses alur bagaimana user dapat melihat lokasi usaha dari sistem informasi geografis.

\section{HASIL DAN PEMBAHASAN}

\subsection{Hasil}

Halaman login merupakan form yang tampil pertama ketika admin mengakses sistem.Halaman login ini digunakan untuk keamanan dalam mengakses menu admin. Halaman login dapat dilihat pada gambar 4.

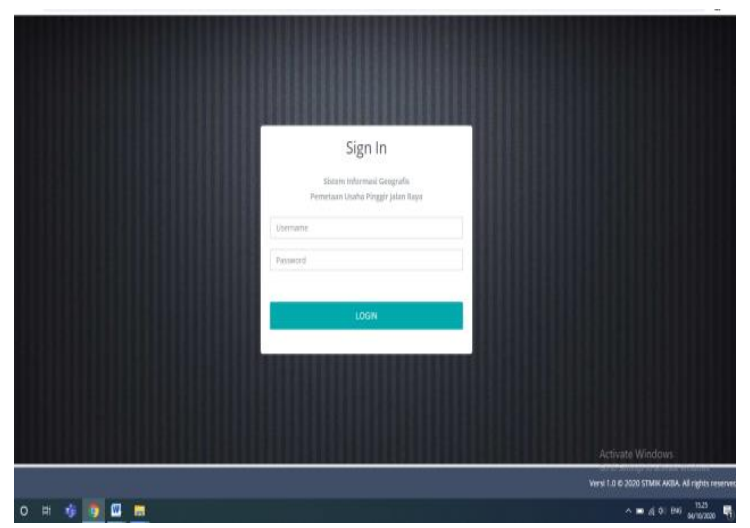

Gambar 4. Halaman Login 
Setelah berhasil login admin dapat memilih menu lokasi. Halaman lokasi dapat dilihat pada gambar 5 .

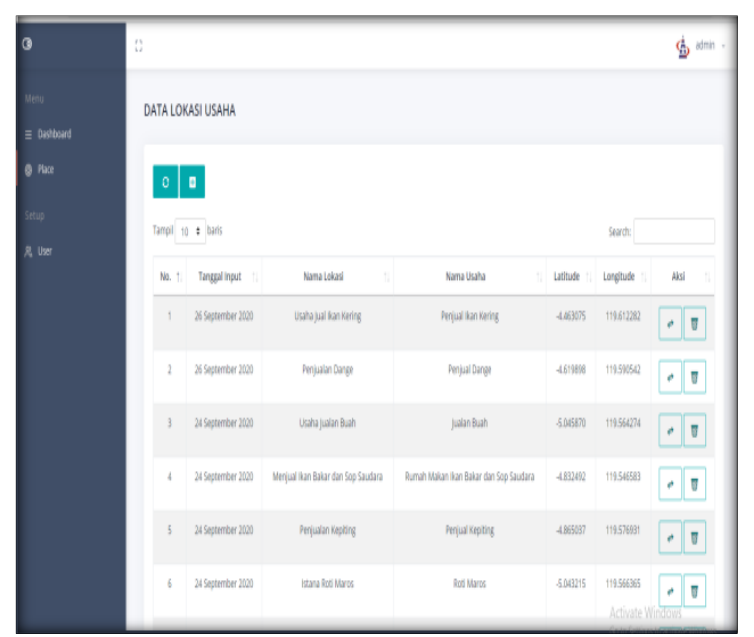

Gambar 5. Data Lokasi Usaha

Dari menu lokasi admin dapat menambah lokasi usaha dengan memilih tombol tambah. Form tambah lokasi dapat dilihat pada gambar 6 .

Gambar 6. Form tambah Lokasi Usaha

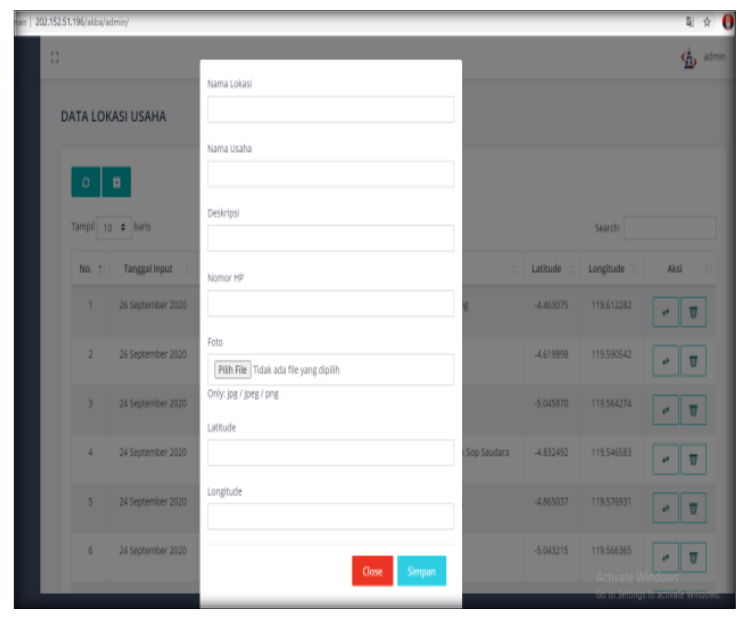

Tampilan lokasi usaha dapat dilihat pada gambar 7 .

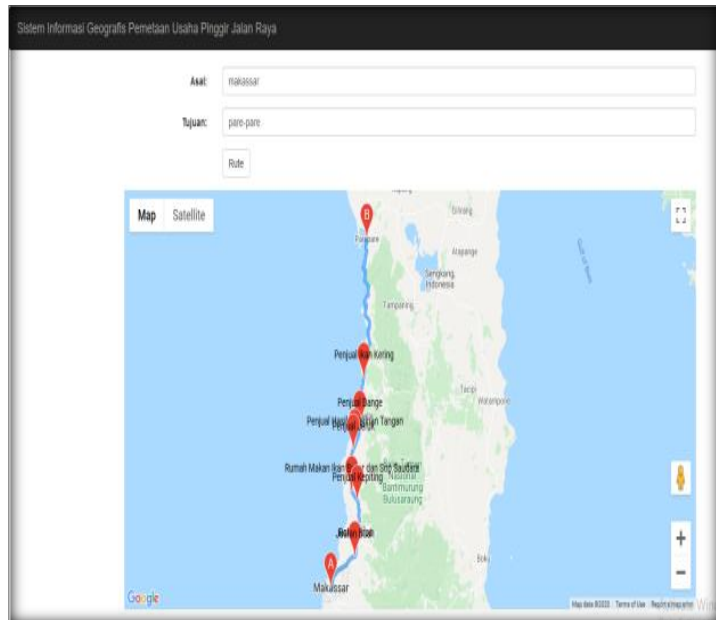

Gambar 7. Tampilan Lokasi Usaha

Pada gambar 7, merupakan tampilan ketika User dalam hal ini masyarakat atau pengguna jalan ketika mengakses sistem dan memasukkan ruta jalan yang ditempu. Setelah tampil lokasi pada sistem user dapat memilih lokasi untuk melihat informasi dari usaha yang ada dalam sistem. Tampilan informasi usaha dapat dilihat pada gambar 8.

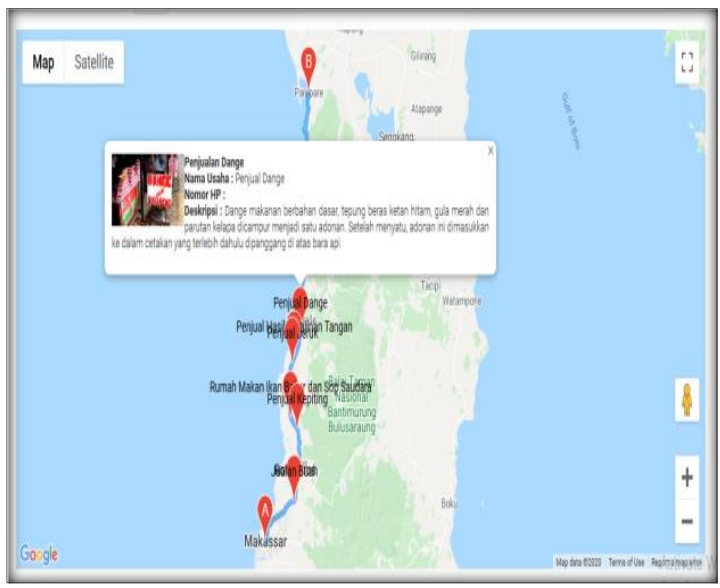

Gambar 8. Tampilan informasi Usaha

\subsection{Pengujian Sistem}

pengujian sistem dilakukan dengan menggunakan metode Blackbox. Hasil pengujian ditunjukkan pada Tabel 1 . 
Tabel 1. Pengujian Blackbox

\begin{tabular}{|c|c|c|c|}
\hline No & Input & Output Yang Diharapkan & Hasil \\
\hline 1 & Admin Akses Sistem & Menampilkan form login & $\begin{array}{c}\text { Sesuai } \\
\text { harapan }\end{array}$ \\
\hline 2 & $\begin{array}{l}\text { Admin memasukkan User } \\
\text { dan Password yang benar }\end{array}$ & Admin berhasil login & $\begin{array}{l}\text { Sesuai } \\
\text { harapan }\end{array}$ \\
\hline 3 & $\begin{array}{l}\text { Admin memasukkan User } \\
\text { dan / atau Password yang } \\
\text { salah }\end{array}$ & Admin gagal login & $\begin{array}{l}\text { Sesuai } \\
\text { harapan }\end{array}$ \\
\hline 4 & Admin pilih menu lokasi & Sistem menampilkan data lokasi & $\begin{array}{l}\text { Sesuai } \\
\text { harapan }\end{array}$ \\
\hline 5 & Admin klick tombol tambah & Sistem menampilkan form tambah lokasi & $\begin{array}{c}\text { Sesuai } \\
\text { harapan }\end{array}$ \\
\hline 6 & Admin klick tombol edit & Sistem menampilkan form edit lokasi & $\begin{array}{c}\text { Sesuai } \\
\text { harapan }\end{array}$ \\
\hline 7 & Admin klick tombol hapus & Sistem menghapus lokasi & $\begin{array}{l}\text { Sesuai } \\
\text { harapan }\end{array}$ \\
\hline 8 & Admin pilih logout & Admin keluar dari sistem & $\begin{array}{c}\text { Sesuai } \\
\text { harapan }\end{array}$ \\
\hline 9 & User akses sistem & Sistem menampilkan lokasi usaha & $\begin{array}{l}\text { Sesuai } \\
\text { harapan }\end{array}$ \\
\hline 10 & User memilih lokasi & Sistem menampilkan informasi usaha & $\begin{array}{l}\text { Sesuai } \\
\text { harapan }\end{array}$ \\
\hline
\end{tabular}

\section{SIMPULAN DAN SARAN}

\subsection{Simpulan}

Adapun kesimpulan dari penelitian ini adalah bahwa sistem yang diracang dapat dapat berjalan sesuai dengan yang diharapkan sehingga dapat memberi informasi kepada masyarkat atau pengguna jalan tentang lokasi dan jenis usaha yang ada di jalan poros Makassar - Pare. Dan dengan adanya informasi dapat meningkatkan penjulan pada usaha-usaha pinggir jalan raya.

\subsection{Saran}

Data koordinat lokasi tempat usaha harus benar-benar valid karena hal ini terkait dengan letak lokasi usaha di jalan poros Makassar - Pare yang ditampilkan dalam bentuk peta secara online. Perlu melakukan update usaha-usaha yang ada. Perlu adanya sosialisasi kepada masyarakat atau pengguna jalan raya.

\section{DAFTAR PUSTAKA}

Anugraha, N., Angriawan, R., \& Mashud, M. (2020). Sistem Informasi Geografis Layanan Publik Lingkup Kota Makassar Berbasis Web. DoubleClick: Journal of Computer and Information Technology, 4(1), 35-40.

Cahyono, M., Satoto, K. I., \&Kridalukmana, R. (2016). 
SistemInformasiManajemenPemesanan

Dan PenjualanPadaUNDIP Distro.

JurnalTeknologi Dan SistemKomputer, 3(3), 370-378.

Ismail Solihin, (2006) Pengantar Bisnis, Pengenalan Peraktis Dan Studi Kasus, Kencana, Jakarta

Masykur, F., Teknik, F., Studi, P., Informatika, T., \& Ponorogo, U. M. (2014). Implementasi sistem informasi geografis menggunakan google maps api dalam pemetaan asal mahasiswa. 5(2), 181-186.

Rais, Ahmad. 2012. "Perancangan dan Pembangunan Sistem Informasi Geografis untuk Pemetaan Titik-Titik Potensi Investasi dibidang Perkebunan dan Pertanian di Kabupaten Pasaman Barat Berbasis Web". Skripsi Sarjana pada FILKOM Universitas Putra Indonesia "YPTK", Padang 